\title{
Paneth cell ablation increases the small intestinal injury during acute necrotizing pancreatitis in rats
}

\author{
LIYAN LIU $^{1 *}$, YUECHENG GUO $^{2 *}$, JUNYUAN ZHENG ${ }^{2}$, YINGYING LU $^{2}$, YUCUI SHEN $^{3}$, \\ CHUNLAN HUANG $^{2}$, YUE ZENG ${ }^{2}$ and XINGPENG WANG ${ }^{2}$ \\ ${ }^{1}$ International Medical Care Center; ${ }^{2}$ Department of Gastroenterology, \\ Shanghai General Hospital of Nanjing Medical University, Shanghai 201620; \\ ${ }^{3}$ Department of Gastroenterology, Shanghai Fourth People's Hospital, Shanghai 200080, P.R. China
}

Received September 3, 2018; Accepted March 29, 2019

DOI: $10.3892 / \mathrm{mmr} .2019 .10274$

\begin{abstract}
The present work aimed to investigate the role of Paneth cells in small intestinal injury during acute necrotizing pancreatitis (ANP) using rat models established by injection of dithizone, a metal chelator of zinc with the ability to selectively ablate Paneth cells. Sprague-Dawley rats were randomly divided into four groups: Sham-operated group, ANP group (3.5\% sodium taurocholate solution, $1 \mathrm{ml} / \mathrm{kg}$ body weight), dithizone group (100 $\mathrm{mg} / \mathrm{kg}$ of body weight) and ANP + dithizone group (sodium taurocholate solution was administered $6 \mathrm{~h}$ after dithizone injection). Each group was further divided into five subgroups $(6,12,24,36$ and $48 \mathrm{~h})$ based on the time period between induction of the model and sample collection. The present results suggested the number of Paneth cells was gradually decreased in the ANP group in a time-dependent manner. Most of the Paneth cells were ablated in the ANP + dithizone group at $6 \mathrm{~h}$, but a subset of Paneth cells recovered after 24-48 h. Compared with the ANP group, combination of dithizone and ANP significantly induced more severe histopathological injuries in the pancreas and distal ileum, with higher Schmidt and Chiu's scores, respectively.
\end{abstract}

Correspondence to: Dr Xingpeng Wang or Dr Yue Zeng, Department of Gastroenterology, Shanghai General Hospital of Nanjing Medical University, 650 New SongJiang Road, Shanghai 201620, P.R. China

E-mail: richardhospital@qq.com

E-mail:carrie@medmail.com.cn

${ }^{*}$ Contributed equally

Abbreviations: ANP, acute necrotizing pancreatitis; AMPs, antimicrobial peptides; DAO, diamine oxidase; IL-, interleukin-; TNF- $\alpha$, tumor necrosis factor- $\alpha$; MODS, multiple organ dysfunction syndrome; SIRS, systemic inflammatory response syndrome; SO, sham-operated; FISH, fluorescence in situ hybridization; $\mathrm{ER}$, endoplasmic reticulum

Key words: acute necrotizing pancreatitis, Paneth cells, dithizone, intestinal barrier, inflammation
Additionally, increased expression levels of tumor necrosis factor- $\alpha$ (TNF- $\alpha)$, interleukin (IL)-1 $\beta$ and IL-17A were detected in the ileum, causing an increase in intestinal permeability, as assessed by a decrease in the expression level of the intestinal tight junction protein occludin and high plasma levels of diamine oxidase and D-lactate. The increase in intestinal permeability led to the translocation of bacteria to the bloodstream, triggering systemic inflammation, as assessed by the increased plasma levels of TNF- $\alpha$, IL-1 $\beta$ and IL-17A, reducing the survival rates of rats, which was $66.7 \%$ and $83.3 \%$ in the ANP + dithizone and the ANP group, respectively. The increase in intestinal endoplasmic reticulum stress, as assessed by high expression levels of binding-immunoglobulin protein and activating transcription factor 6 , may be one mechanism associated with Paneth cells loss and intestinal barrier impairment during ANP. Collectively, the present study suggested that the absence of Paneth cells may be an important factor involved in intestinal injury, promoting the progression of ANP.

\section{Introduction}

Acute necrotizing pancreatitis (ANP) is a common and potentially lethal disease affecting the digestive system with an estimated incidence of 5-100 per 100,000 people, $(1,2)$ and mortality rates of $2-30 \%(1,3,4)$. Accumulating evidence has demonstrated that the majority of the morbidity and mortality is a consequence of the malfunction of the intestinal barrier, which leads to increased intestinal permeability and subsequent translocation of bacteria or endotoxin from the intestinal lumen to extra-intestinal sites and to the systemic circulation (5-7). Bacterial translocation may induce secondary infections, systematic inflammation response syndrome (SIRS), multiple organ dysfunction syndrome (MODS) and multiple organ failure (MOF) (5-7). Therefore, understanding the mechanisms underlying intestinal barrier dysfunction in ANP is important to develop effective preventive and therapeutic strategies.

Accumulating evidence has demonstrated that excessive apoptosis and reduced regeneration of intestinal epithelial cells may contribute to the impairment of intestinal barrier functions (8-12). Therefore, caspase inhibitors able to repress 
apoptosis, such as carbobenzoxy-valyl-alanyl-aspartyl-[Omethyl]- fluoromethylketone (8), and bone marrow-derived mesenchymal stem cells (11) have been reported to have protective effects on small intestinal injury associated with ANP. However, their clinical application remains limited, and further studies are required to identify novel therapies to improve the integrity of the intestinal barrier.

In fact, the intestinal epithelial cells can be repaired by expansion and differentiation of leucine rich repeat containing G protein-coupled receptor 5 (LGR5)-positive epithelial stem cells of the small intestine (13). Paneth cells are located at the base of the small intestinal crypts and are the major component of the epithelial niche, being involved in the function of the adjacent stem cells by expressing signaling molecules, such as Wnt3 $(14,15)$. Reduced secretion of Wnt3 in Paneth cells results in the senescence of intestinal stem cells, whereas upregulating the expression levels of Wnt3a restores the regenerative capacity of intestinal stem cells (16). In addition to their role in stem cell proliferation, a previous study demonstrated that Paneth cells support stem cell functions by providing lactate, which is involved in the mitochondrial oxidative phosphorylation of LGR5-positive epithelial stem cells (17). By contrast, inhibition of glycolysis in Paneth cells severely affects stem cell functions, resulting in impaired organoid formation (17). In addition, mature Paneth cells are responsible for the synthesis and secretion of various antimicrobial peptides (AMPs), including regenerating islet-derived protein $3 \gamma, \alpha$-defensins, lysozyme and phospholipase A2, which have a high antimicrobial activity and protect the host against intestinal pathogen colonization and subsequent inflammatory-associated injury (18-20). In the present study, it was hypothesized that the absence of Paneth cells may be a possible factor involved in the progression of ANP, and increasing the number of Paneth cells may represent a novel therapeutic approach to treat ANP (18). This hypothesis was investigated in our previous preliminary studies, which identified that the circulating levels of AMPs and the number of Paneth cells were gradually reduced following ANP induction, and were significantly decreased after $48 \mathrm{~h}(21,22)$.

The present study aimed to investigate the role of Paneth cells in ANP by using dithizone, a metal chelator of zinc able to selectively ablate Paneth cells $(23,24)$. The present study suggested disrupting Paneth cells may have an important role in the development of intestinal barrier dysfunction in ANP.

\section{Materials and methods}

Animals. All the experimental protocols were approved by The Animal Care and Use Committee of The Shanghai General Hospital of Nanjing Medical University and the experiments were performed in accordance with the institutional animal care guidelines. All surgeries were performed under $2 \%$ sodium pentobarbital anesthesia $(50 \mathrm{mg} / \mathrm{kg})$ to minimize suffering of the rats.

In total, 120 male Sprague-Dawley (weight, 150-180 g; mean age, 5 weeks) rats were purchased from Shanghai SLAC Laboratory Animal Co., Ltd. All rats were housed at $23-25^{\circ} \mathrm{C}$ room temperature and $40-60 \%$ relative humidity under a $12-\mathrm{h}$ light/dark cycle. All animals had free access to food and water.
Animal groups and procedures. Sprague-Dawley rats were randomly divided into four groups ( $\mathrm{n}=30$ in each group) as follows: i) Sham-operated (SO) group; ii) ANP group; iii) dithizone group; and iv) ANP + dithizone combination group. Each group was further divided into five subgroups $(6,12,24,36$ and $48 \mathrm{~h}$ ) based on the time period between construction of the model and sample collection ( $\mathrm{n}=6$ in each group).

To induce ANP, laparotomy was performed in rats under anesthesia through a $2-\mathrm{cm}$-long midline incision. A needle (diamenter, $0.55 \mathrm{~mm}$ ) was inserted into the biliopancreatic duct and connected with a transfusion converter. Retrograde injection of $3.5 \%$ sodium taurocholate solution $(35 \mathrm{mg} / \mathrm{kg}$ body weight, $0.2 \mathrm{ml} / \mathrm{min}$ ) into the biliopancreatic duct was performed as previously described (25). Rats in the SO group underwent a sham operation and were injected with normal saline solution. Dithizone (Sigma-Aldrich; Merck KGaA) was dissolved in saturated lithium carbonate solution $(\mathrm{pH} 11.8$, $10 \mathrm{mg} / \mathrm{ml}$ ) and maintained at $70^{\circ} \mathrm{C}$ for $20 \mathrm{~min}$, as previously described (23). Rats in the dithizone group were injected with dithizone $(100 \mathrm{mg} / \mathrm{kg}$ body weight) via the tail vein for $3 \mathrm{~min}$. The rats were not fasted prior to the injections. Rats in the ANP + dithizone group were injected with dithizone $6 \mathrm{~h}$ before retrograde injection of $3.5 \%$ sodium taurocholate solution.

Rats were sacrificed by exsanguination under deep anesthesia at $6,12,24,36$ or $48 \mathrm{~h}$ after ANP induction or ANP + dithizone injection. Blood samples were collected from the abdominal aorta. The pancreas and the distal ileum were rapidly fixed in $10 \%$ neutral buffered formaldehyde solution at room temperature for $48 \mathrm{~h}$ for histological examination. Segments of the distal ileum were isolated and snap-frozen in liquid nitrogen, then stored at $-80^{\circ} \mathrm{C}$ for further biochemical analysis.

Histological examination. Pancreatic and ileal tissues samples were fixed with $10 \%$ neutral buffered formaldehyde solution at room temperature for $48 \mathrm{~h}$, embedded in paraffin, cut into $4-\mu \mathrm{m}$-thick sections and stained with hematoxylin and eosin for $5 \mathrm{~min}$ at room temperature. Pathological changes in the pancreas and small intestine were observed under a light microscope (magnification, x100) and evaluated by an experienced pathologist according to the Schmidt pancreas score (26) and Chiu's small intestine score systems (27). In addition, the number of Paneth cells in each crypt was determined using the ImageJ software (version 1.8.0; National Institutes of Health) analyzing eight fields per slide (28).

Immunofluorescence. Immunofluorescence analysis was performed to analyze the protein expression level of lysozyme. The ileal tissues samples were fixed with $10 \%$ neutral buffered formaldehyde solution for $48 \mathrm{~h}$ at room temperature, embedded in paraffin and sectioned (thickness, $4 \mu \mathrm{m}$ ). After deparaffinization, rehydration was performed at room temperature using sequential incubations of $100 \%$ xylene for $15 \mathrm{~min}$, $100 \%$ xylene for $15 \mathrm{~min}, 100 \%$ ethanol for $5 \mathrm{~min}, 100 \%$ ethanol for $5 \mathrm{~min}, 85 \%$ ethanol for $5 \mathrm{~min}, 75 \%$ ethanol for $5 \mathrm{~min}$ and running water for $1 \mathrm{~min}$. Subsequently, antigen retrieval was performed by incubating the sections in EDTA buffer ( $\mathrm{pH}$ 8.0; cat. no. G1206; Servicebio Technology Co., Ltd.). The sections were then heated using a microwave oven. Following blocking with $3 \%$ BSA for $30 \mathrm{~min}$ at room temperature, the sections 
were incubated with a primary antibody specific for lysozyme (1:1,000; cat. no. A0099; Dako; Agilent Technologies, Inc.) overnight at $4^{\circ} \mathrm{C}$. Sections were then incubated with Cy3-conjugated goat anti-rabbit secondary antibody (1:300; cat. no. GB21303; Servicebio Technology Co., Ltd.) for $50 \mathrm{~min}$ at room temperature in the dark. The nuclei were counterstained with $1 \mathrm{mg} / \mathrm{ml}$ DAPI (1:700; cat. no. G1012; Servicebio Technology Co., Ltd.) for $10 \mathrm{~min}$ at room temperature. Seven sections per rats were analyzed, and representative images were acquired using a fluorescence microscope (magnification, x400) (Leica DM5500B; Leica Microsystems GmbH) and the Image-Pro Plus software (version 3.0; Media Cybernetics).

Western blotting. The protein expression levels of occludin, glucose-regulated protein, $78 \mathrm{kDa}$ [also known as binding-immunoglobulin protein (BIP)] and activating transcription factor 6 (ATF6) were assessed by western blot analysis. Isolated distal ileum samples were lysed using ice-cold RIPA lysis buffer (Thermo Fisher Scientific, Inc.). The homogenates were then centrifuged at 24,170 x g for $10 \mathrm{~min}$ at $4^{\circ} \mathrm{C}$ and the supernatants were collected to measure the protein expression. The protein concentration was determined using a bicinchoninic acid (BCA) protein assay kit (Beyotime Institute of Biotechnology). The extracts were heated at $100^{\circ} \mathrm{C}$ for $10 \mathrm{~min}$. Equal amounts of extracted protein samples $(20 \mu \mathrm{g})$ were separated by SDS-PAGE on $15 \%$ gels and then transferred to PVDF membranes. Fat-free milk $(5 \%)$ was used to block the membranes for $60 \mathrm{~min}$ at room temperature. The membranes were incubated overnight at $4^{\circ} \mathrm{C}$ with the following primary antibodies: Rabbit anti-occludin (1:1,000; cat. no. ab167161, Abcam), rabbit anti-BIP (1:1,000; cat. no. 21403-1-AP, ProteinTech Group, Inc.) and rabbit anti-ATF6 (1:1,000; cat. no. A12570, ABclonal Biotech Co., Ltd.). $\beta$-actin (1:3,000; cat. no. AA128, Beyotime Institute of Biotechnology) was used as the loading control. Subsequently, the membranes were incubated with a horseradish peroxidase-conjugated secondary antibody $(1: 3,000$; cat. no. GB23302; Servicebio Technology Co., Ltd.) for $60 \mathrm{~min}$ at room temperature. Protein bands were visualized using an ECL kit (Pierce; Thermo Fisher Scientific, Inc.) and quantified with the Alpha Imager Software (version 4.0; Alpha Innotech Corporation).

Measurement of D-lactate and diamine oxidase (DAO) in plasma. Blood samples collected from the abdominal aorta were centrifuged at $1,511 \mathrm{x}$ for $15 \mathrm{~min}$ at $4^{\circ} \mathrm{C}$ to obtain the plasma. D-lactate plasma levels were determined using an ELISA kit (cat. no. 26392, Shanghai USEN Biological Technology Co., Ltd.). DAO activity in plasma was measured using a commercial kit (cat. no. A088-1, Nanjing Jiancheng Bioengineering Institute) according to the manufacturer's protocol.

Fluorescence in situ hybridization (FISH). The ileal tissues samples were collected from the four experimental groups $24 \mathrm{~h}$ after injection. The samples were fixed with $4 \%$ paraformaldehyde for $24 \mathrm{~h}$ at room temperature, embedded in paraffin and cut into $4-\mu$-thick sections. The sections were then mounted onto glass slides and evaluated by FISH. The slides were deparaffinized at room temperature using sequential incubations in
$100 \%$ xylene for $15 \mathrm{~min}, 100 \%$ xylene for $15 \mathrm{~min}, 100 \%$ ethanol for $5 \mathrm{~min}, 100 \%$ ethanol for $5 \mathrm{~min}, 85 \%$ ethanol for $5 \mathrm{~min}$ and $75 \%$ ethanol for $5 \mathrm{~min}$. Samples were then washed using diethyl pyrocarbonate-treated water at room temperature. To assess the localization of bacteria, the universal bacterial probe EUB-338 (sequence, 5'-GCTGCCTCCGTAGGAGT-3'; Servicebio Technology Co., Ltd.) was labeled at the 5'-end with the red-fluorescent dye Cy3 (Sigma-Aldrich; Merck $\mathrm{KGaA}$ ). Slides were incubated overnight at $46^{\circ} \mathrm{C}$ in a hybridization buffer (cat. no. G3016-3; Servicebio Technology Co., Ltd.) containing the EUB338 probe (8 ng/ul). After hybridization, samples were washed using wash buffer (hybridization buffer without SDS) and rinsed with sterile water, air-dried, and mounted with DAPI on a coverslip. The bacteria were visualized by FISH and DAPI staining using a fluorescence microscope (magnification, x400) (Leica DM5500B; Leica Microsystems $\mathrm{GmbH}$ ) and the images were acquired and analyzed with the Image-Pro Plus software (version 3.0; Media Cybernetics,).

Measurement of cytokines levels in plasma and in the distal ileum. The distal ileums (1-cm-long segment) were removed and homogenized in RIPA buffer (Beyotime Institute of Biotechnology) containing $1 \%$ protease inhibitor. The homogenates were centrifuged at $24,170 \mathrm{x}$ g for $10 \mathrm{~min}$ at $4^{\circ} \mathrm{C}$ and the supernatants were collected and stored at $-80^{\circ} \mathrm{C}$. The concentrations of protein were detected using a BCA protein assay kit (Beyotime Institute of Biotechnology). The protein expression levels of tumor necrosis factor- $\alpha$ (TNF- $\alpha$ ), interleukin (IL)-1 $\beta$ and IL-17A in the plasma and the distal ileum tissues were measured using ELISA kits (eBioscience; cat. nos. BMS622, BMS630 and BMS635 for TNF- $\alpha$, IL-1 $\beta$ and IL-17A, respectively; Thermo Fisher Scientific, Inc.) as previously described (29).

Statistical analysis. Statistical analysis was performed using SPSS software (version 11.0; SPSS Inc.). Data (except overall survival data) are presented as the mean \pm SD for continuous variables and percentage for categorical variables. Experiments were performed in triplicate. Comparisons of continuous variables among multiple groups were analyzed using a one-way ANOVA followed by Tukey's post hoc test. Survival rate among the groups was assessed using the $\chi^{2}$ or Fisher's exact test. $\mathrm{P}<0.05$ was considered to indicate a statistically significant difference.

\section{Results}

Injection of dithizone ablates Paneth cells in the small intestine. Morphology of the distal ileum and the presence of Paneth cells were assessed by histological analyses (Fig. 1A). Paneth cells containing granules were observed at the base of the intestinal crypts in the SO group at each time point. Paneth cells were gradually ablated in a time-dependent manner in the ANP group, and were significantly decreased at 36 and $48 \mathrm{~h}$ after sodium taurocholate injection (Fig. 1B), consistently with our previous study (21). Mice treated with dithizone exhibited significantly fewer Paneth cells in the crypt, with disorganized granules or without granules; particularly at 6 and $12 \mathrm{~h}$. The present results are in line with a previous study demonstrating 

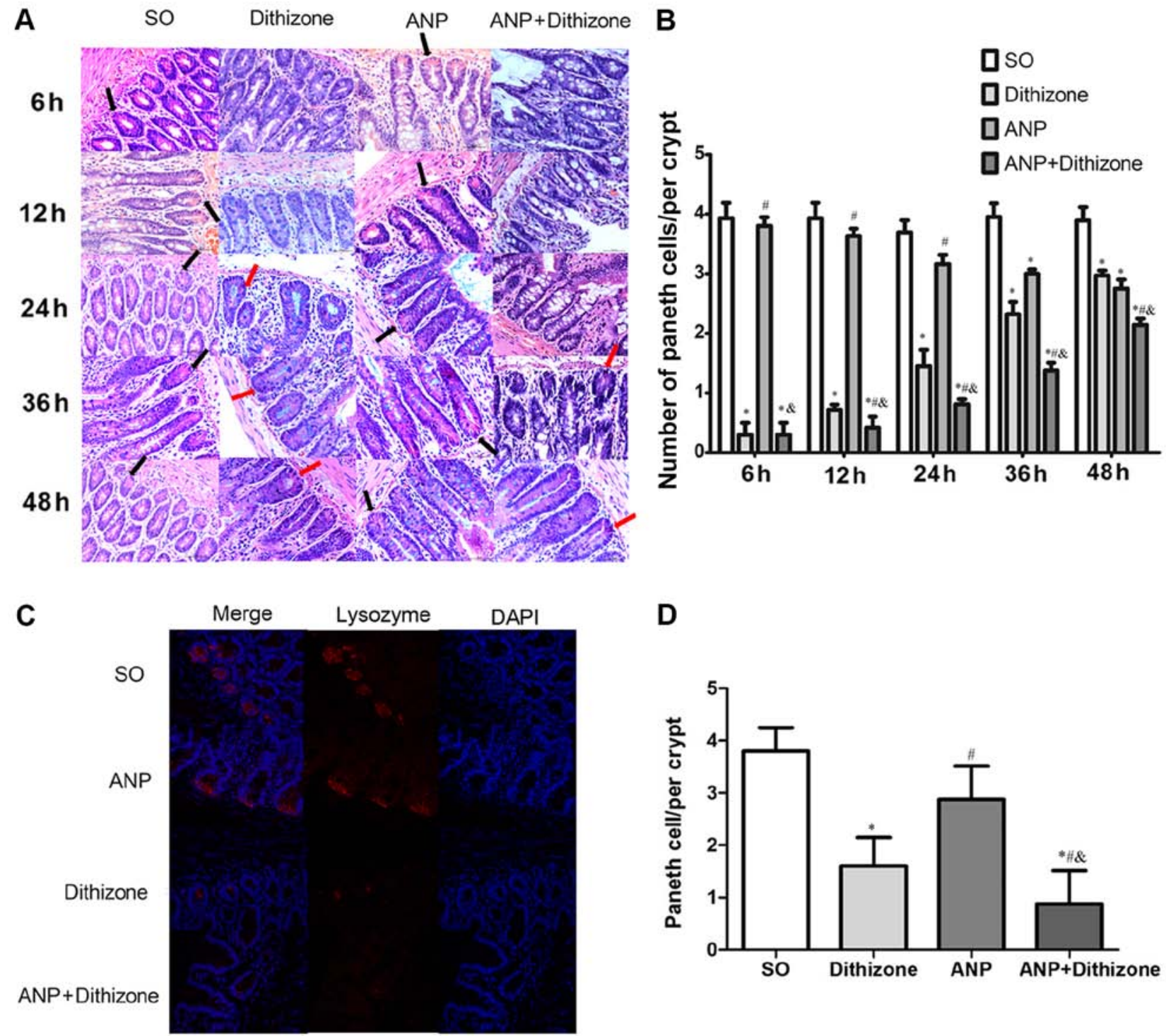

Figure 1. Changes in the number of Paneth cells in the distal ileum of rats following dithizone injection and/or ANP induction. (A) Histological analysis of the alterations in Paneth cell number and morphology at 6,12,24, 36 and $48 \mathrm{~h}$. Paneth cells are indicated by arrows. Red arrows indicate dithizone treatment group. Black arrows indicate groups without dithizone treatment. Magnification, x400. (B) Quantification of the number of Paneth cells at each time point, as assessed by hematoxylin and eosin staining. (C) Immunofluorescence results using the Paneth cell biomarker lysozyme (red) was performed to observe the number of Paneth cells at $24 \mathrm{~h}$ in the four experimental groups. Nuclei counterstained with DAPI (blue). Magnification, $\mathrm{x} 400$. (D) Quantification of the immunofluorescence assay. $\mathrm{n}=6$ in each group. In total, 8 randomly-selected fields of view were analyzed in each group. ${ }^{*} \mathrm{P}<0.05$ vs. SO group; ${ }^{\text {}} \mathrm{P}<0.05$ vs. dithizone group; ${ }^{\circledR} \mathrm{P}<0.05$ vs. ANP group. SO, sham-operated group; ANP, acute necrotizing pancreatitis.

that dithizone causes selective Paneth cell ablation (23). However, the numbers of Paneth cells and granule morphology was partly recovered after 24 and $48 \mathrm{~h}$ in the dithizone and ANP + dithizone groups (Fig. 1B). The numbers of Paneth cells were not significantly different between the dithizone and the ANP groups at 36 and $48 \mathrm{~h}$, but there was a statistical difference between the ANP group and the ANP + dithizone group. Therefore, $24 \mathrm{~h}$ was selected as the ideal point to examine the effects of dithizone on Paneth cells. Subsequently, immunofluorescence for lysozyme, an AMP secreted specifically by Paneth cells that was used to investigate the amount and the function of Paneth cells (30), was performed at $24 \mathrm{~h}$ to further quantify the number of Paneth cells (Fig. 1C). The present results suggested that rats in the dithizone + ANP group exhibited the lowest number of lysozyme-positive cells in the crypt of the ileum (Fig. 1D).
Ablation of Paneth cells decreases the survival rate of ANP model rats. In total, six rats were sacrificed at each time point to collect the corresponding samples, and thus the number of total rats was 30, 24, 18, 12 and 6 at 6, 12, 24, 36 and $48 \mathrm{~h}$, respectively. Then, the survival rates were calculated for each time point in each group (Fig. 2). In the SO group, all rats survived, and the survival rate was $100 \%$. In the dithizone group, one rat died at $6 \mathrm{~h}$, and the survival rate was $96.7 \%$ (29/30). For the other time points, the survival rate in the dithizone group was $100 \%$. In the ANP group, the survival rate at 6, 12 and $24 \mathrm{~h}$ was $100 \%$; however, one rat died at $36(11 / 12$; $91.7 \%$ survival rate) and $48 \mathrm{~h}(5 / 6 ; 83.3 \%$ survival rate). In the $\mathrm{ANP}+$ dithizone group, the numbers of deceased rats were as follows: Three at $6 \mathrm{~h}(27 / 30 ; 90 \%$ survival rate), three at $12 \mathrm{~h}$ (21/24; 87.5\% survival rate), two at $24 \mathrm{~h}(16 / 18 ; 88.9 \%$ survival rate), two at $36 \mathrm{~h}(10 / 12 ; 83.3 \%$ survival rate) and two at $48 \mathrm{~h}$ 


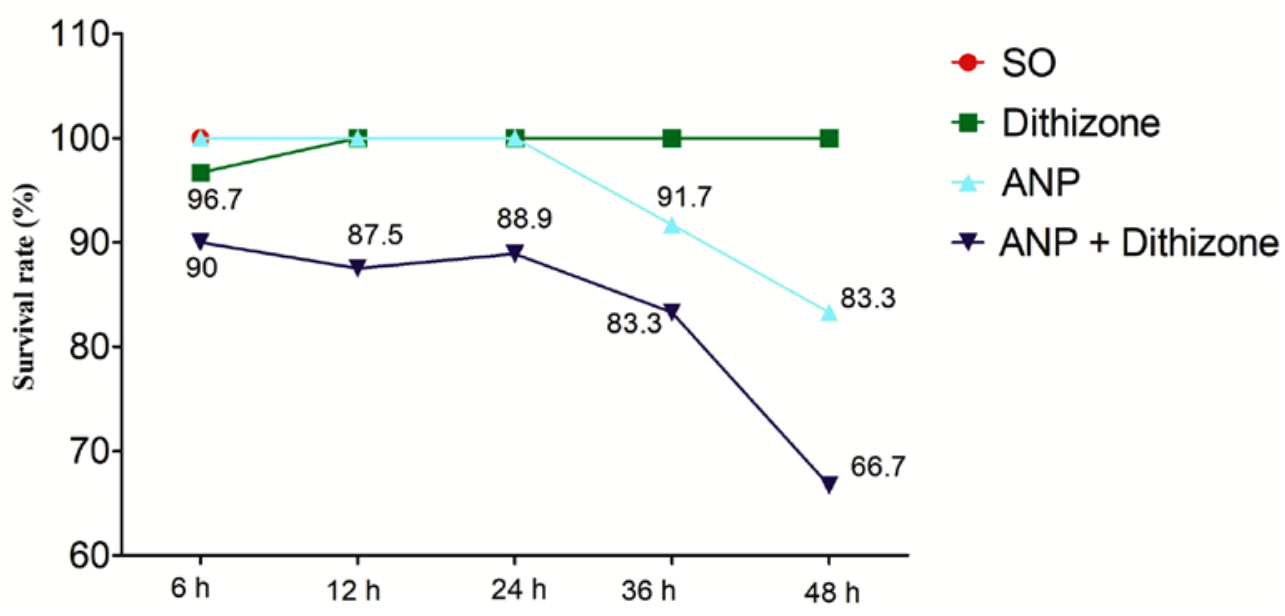

Figure 2. Survival rate for the four experimental groups. SO, sham-operated group; ANP, acute necrotizing pancreatitis.

(4/6; 66.7\% survival rate). Although no significant statistical different survival rates were observed among different groups, the lower survival rate in the ANP + dithizone group at $48 \mathrm{~h}$ suggested that systemic damage was more severe in ANP rats injected with dithizone.

Ablation of Paneth cells induces inflammation-associated pathological changes in the pancreas and distal ileum. The pancreatic damage in all ANP rats was characterized by enlarged interlobular interspaces, necrotic regions, hemorrhage and infiltration of inflammatory cells, as assessed by light microscopy (Fig. 3A). Quantitative analysis demonstrated that, in the ANP group, the Schmidt pathological score gradually increased in a time-dependent manner (Fig. 3B). Additionally, at each time point, the Schmidt score in the ANP group was significantly higher compared with the SO and dithizone groups. Dithizone treatment in ANP models further aggravated the pancreatic lesions, and the pathological score was significantly higher than the ANP group at 24 and $36 \mathrm{~h}$. The present results suggested that Paneth cells ablation may play an important role in the development of ANP.

Histopathological changes were observed in the distal ileum in all treated rats, and the observed defects included mucosal edema, villi shortening, infiltration of inflammatory cells, hemorrhage, ulceration, destruction of villous integrity and local tissue necrosis separated by normal tissue, which were particularly visible in the ANP + dithizone group (Fig. 3C). Subsequently, quantitative pathological scores of the distal ileum were calculated. Consistently with the development of pancreatitis, the Chiu's score of the ANP group was gradually increased in a time-dependent manner (Fig. 3D). Rats in the dithizone group showed mild lesions in the intestinal mucosa compared with the SO group at 12, 36 and $48 \mathrm{~h}$. In the dithizone group, the intestinal injury score ranged between 1.3 and 1.6 and no significant changes were detected among time points. ANP rats injected with dithizone exhibited the highest Chiu's score at each time point, and the score was significantly higher compared with the other groups (Fig. 3D). In line with the pathological scores, the protein expression levels of proinflammatory cytokines, including
TNF- $\alpha$, IL-1 $\beta$ and IL-17A, in the distal ileum were also significantly increased in the ANP and the ANP + dithizone groups compared with the SO group (Fig. 4). The protein expression level of IL-1 $\beta$ in the ANP group was significantly higher than the SO group between 6 and $48 \mathrm{~h}$. By contrast, the expression levels of TNF- $\alpha$ and IL-17A were significantly higher in the ANP group compared with the SO group between 24 and $48 \mathrm{~h}$. There were no significant differences in most of the protein expression levels of IL-1 $\beta$, IL-17A and TNF- $\alpha$ between ANP and ANP + dithizone groups after $24 \mathrm{~h}$, with TNF- $\alpha$ at $48 \mathrm{~h}$ being the only exception (Fig. 4).

Ablation of Paneth cells induces alterations in the intestinal barrier permeability. Tight junctions are the structural components that regulate intestinal epithelial permeability (31). Therefore, the tight junction protein occludin is frequently used as a biomarker for assessing intestinal permeability (32). In the present study, western blot analysis was performed to detect the protein expression level of occludin in the distal ileum in the four experimental groups (Fig. 5A). The present results suggested that the protein expression level of occludin was not significantly altered between the SO and dithizone groups, and remained stable over time. The protein expression level of occludin was downregulated in the ANP group in a time-dependent manner. Compared with the ANP group, the protein expression levels of occludin were significantly reduced in ANP rats injected with dithizone at $6 \mathrm{~h}$ (Fig. 5B).

DAO is an enzyme located almost exclusively in the mature upper villus cells of the intestinal mucosa (33). D-lactate is a metabolite synthesized specifically by intestinal bacteria (34). High levels of DAO (33) and D-lactate (34) in the plasma have been reported as indicators of permeability and damage in the intestine. In the present study, the plasma levels of DAO and D-lactate were detected in the four experimental groups (Fig. 5C and D). Compared with the SO group, the ANP and the ANP + dithizone groups exhibited significantly higher plasma levels of DAO and D-lactate at 24, 36 and $48 \mathrm{~h}$. The plasma levels of DAO and D-lactate were significantly higher in the ANP + dithizone group compared with the ANP group at 6,12 and $24 \mathrm{~h}$ after ANP induction. 


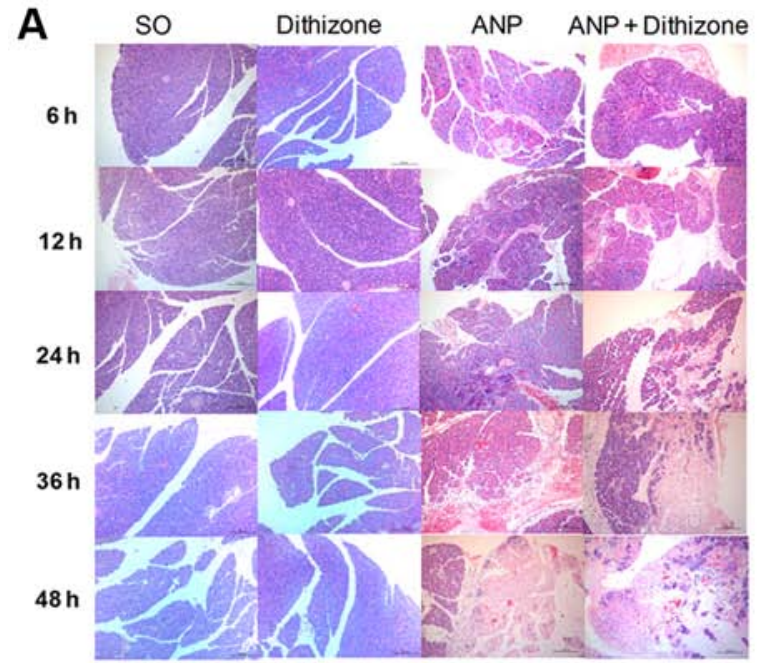

B
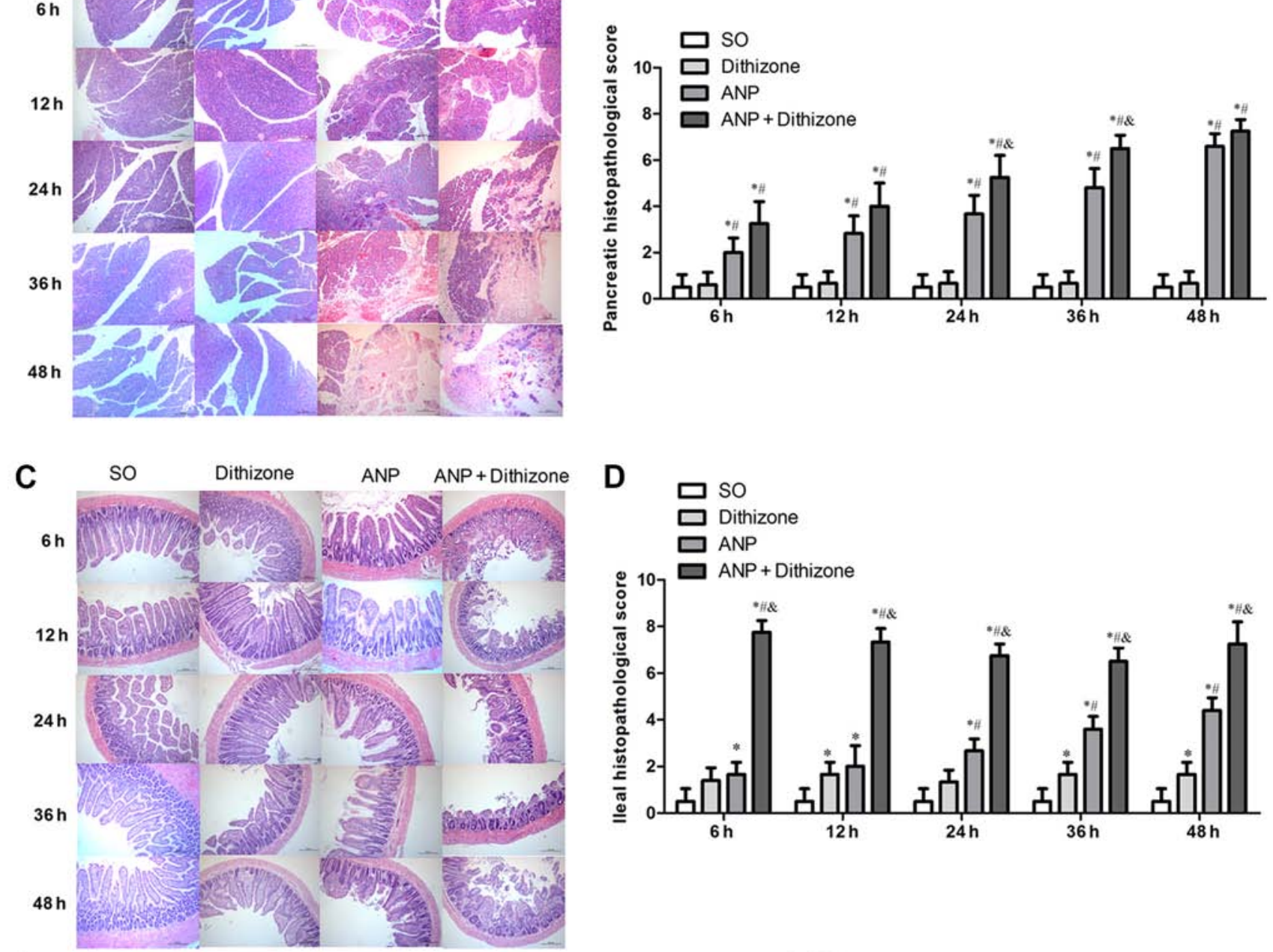

Figure 3. Pathological changes in the pancreas and distal ileum of rats following dithizone injection and/or ANP induction. (A) Representative histological images of the pancreas at 6, 12, 24, 36 and $48 \mathrm{~h}$. Magnification, x100. (B) Pathological scores of the pancreas according to the Schmidt method. (C) Representative histological images of the distal ilea at 6,12, 24, 36 and $48 \mathrm{~h}$. Magnification, x100. (D) Pathological scores of the distal ileum according to the Chiu's small intestine score system. $\mathrm{n}=6$ in each group. In total, 8 randomly-selected fields of view were analyzed in each group. ${ }^{*} \mathrm{P}<0.05$ vs. SO group; ${ }^{\#} \mathrm{P}<0.05$ vs. dithizone group; ${ }^{\&} \mathrm{P}<0.05$ vs. ANP group. SO, sham-operated group; ANP, acute necrotizing pancreatitis.

Ablation of Paneth cells leads to translocation of intestinal bacteria and triggers systemic inflammation. At $24 \mathrm{~h}$ after ANP induction, the distal ileum tissues were paraffin-embedded and sectioned, and FISH was performed in the four experimental groups using the universal bacterial probe EUB-338. No bacterial-associated fluorescence expression was detected in the SO group. There was a slight increase in bacterial-associated fluorescence in a subset of intestinal villi in the dithizone group. The fluorescent signal increased significantly in the ANP group, mainly in the intestinal villi. The fluorescent signal in the ANP + dithizone group was the strongest among the four groups and the bacterial probe was observed primarily at the base of the intestinal lamina propria and crypts, suggesting a translocation of intestinal microbiota (Fig. 6). The present results suggested that intestinal microbiota translocation increases following Paneth cell depletion in ANP rats.

Plasma levels of TNF- $\alpha$, IL-1 $\beta$ and IL-17A levels were measured to evaluate the systemic inflammation. The plasma levels of TNF- $\alpha$, IL-1 $\beta$ and IL-17A in the SO and dithizone groups did not change significantly over time (Fig. 7). However, the plasma levels of these cytokines increased significantly in the ANP group and the ANP + dithizone group in a time-dependent manner. Additionally, the levels were particularly high in the ANP + dithizone group. There was no significant difference in the plasma levels of IL- $1 \beta$, TNF- $\alpha$ and IL-17A between the ANP + dithizone group and the ANP group at $48 \mathrm{~h}$, consistently with the intestinal barrier permeability phenotype (Fig. 5A and B).

Endoplasmic reticulum (ER) stress and its implications in the pathogenesis associated with Paneth cell dysfunction and ANP. Previous studies have suggested that prolonged ER stress triggered in proliferative progenitor cells, such as Paneth cells and intestinal stem cells, may lead to persistent apoptosis of intestinal epithelial cells, causing the disruption of the mucosal barrier function and proinflammatory responses, resulting in the progression of inflammatory intestinal diseases (35-37). Therefore, in the present study, the expression levels of proteins associated with ER stress, such as BIP and 

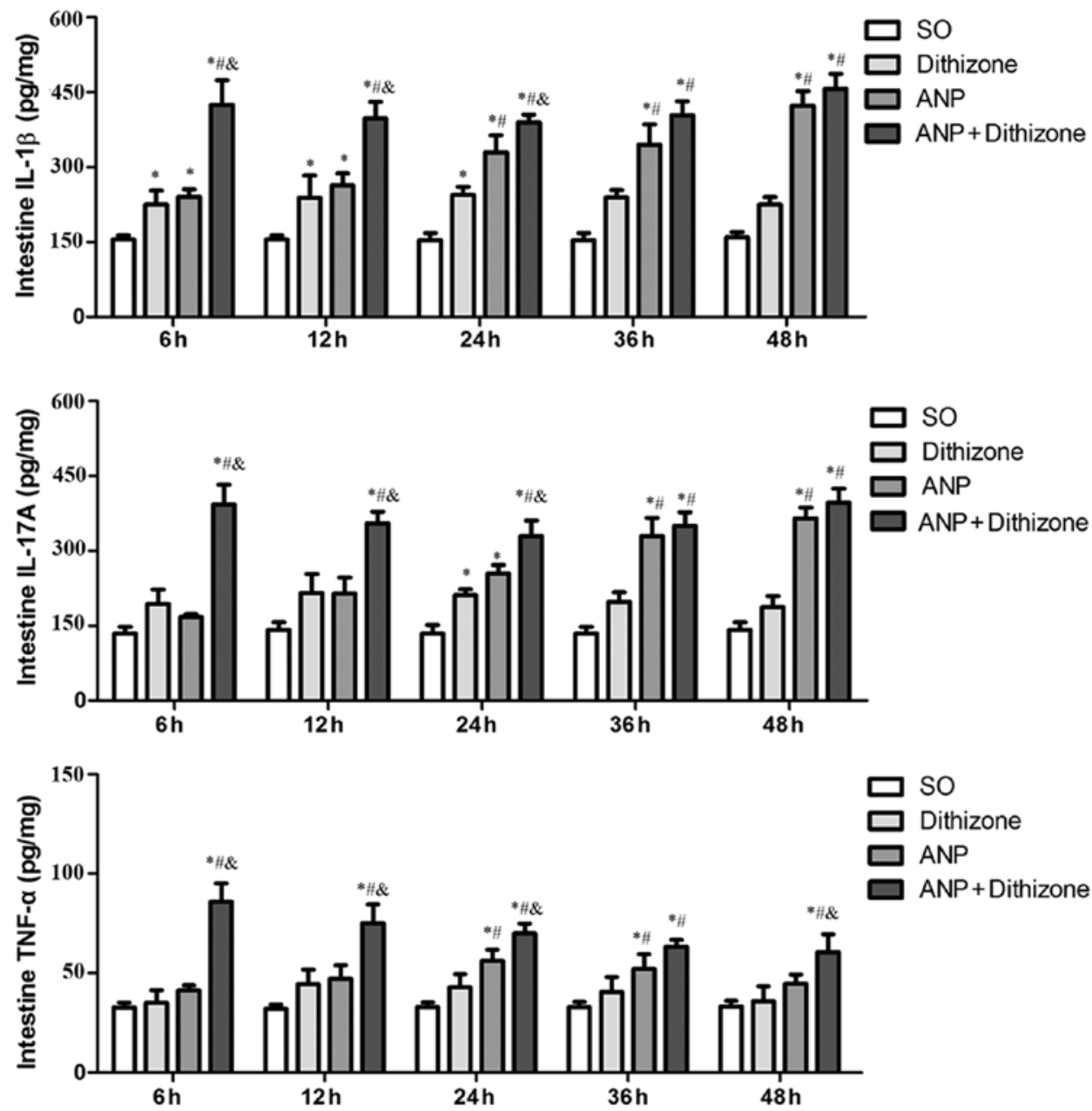

Figure 4. Expression levels of inflammatory cytokines in the distal ileum of rats, as measured by ELISA. ${ }^{*} \mathrm{P}<0.05$ vs. SO group; ${ }^{\#} \mathrm{P}<0.05$ vs. dithizone group; ${ }^{\&} \mathrm{P}<0.05$ vs. ANP group. SO, sham-operated group; ANP, acute necrotizing pancreatitis; TNF- $\alpha$, tumor necrosis factor- $\alpha$; IL, interleukin.

ATF6, were detected in distal ilea using western blotting. The protein expression levels of BIP and ATF6 between the SO and dithizone groups were not significantly different and did not change over time (Fig. 8). By contrast, the protein expression levels of BIP and ATF6 were upregulated in the ANP and ANP + dithizone groups and their protein expression levels increased in a time-dependent manner. The protein expression levels of BIP and ATF6 in the ANP + dithizone group were significantly higher than in the ANP group at 6 and $24 \mathrm{~h}$. The present findings suggested that loss of Paneth cells may be associated with the severity of ER stress in ANP.

\section{Discussion}

Previous studies have used the zinc chelator dithizone to deplete Paneth cells, and it was demonstrated that Paneth cell ablation causes the development of necrotizing enterocolitis, promoting small intestinal injury $(24,38)$. Our previous studies reported that rats with ANP exhibited intestinal barrier injury in addition to decreased levels of AMPs synthesized by Paneth cells, including lysozyme and $\alpha$-defensin $5(21,22)$. Therefore, in the present study, it was hypothesized that the absence of Paneth cells may be a crucial mechanism for intestinal barrier dysfunction in ANP. To the best of our knowledge, the present study is the first to show ablation of Paneth cells, achieved $6 \mathrm{~h}$ after dithizone administration as previously shown by Sawada et al (23), in a rat model for ANP that was established by retrograde injection of sodium taurocholate. The ANP rats injected with dithizone exhibited more severe intestinal damage than the ANP group between 6 and $48 \mathrm{~h}$ after injection of sodium taurocholate. Previous studies have demonstrated that intestinal damages may induce an increase in the intestinal permeability and subsequent translocation of bacteria to the bloodstream, which may lead to SIRS, MODS and MOF, and in severe cases, death (5-7). Therefore, the present study investigated the protein expression level of the intestinal tight junction protein occludin, which was found to be significantly decreased by ANP + dithizone. Additionally, plasma levels of DAO, D-lactate and inflammatory cytokines, including TNF- $\alpha$, IL-1 $\beta$ and IL-17A, were significantly increased in the ANP + dithizone group compared with the ANP group, particularly between 6 and $24 \mathrm{~h}$. Additionally, the survival rate of the ANP + dithizone group was decreased compared with the ANP group. In various assays performed in the present study, no significant differences were detected between the ANP + dithizone and ANP groups at 36 and $48 \mathrm{~h}$ after ANP induction. This effect may be due to two main factors; the Paneth cells may recover after dithizone injection in a time-dependent manner, as previously demonstrated by Sawada et al (23) and observed 


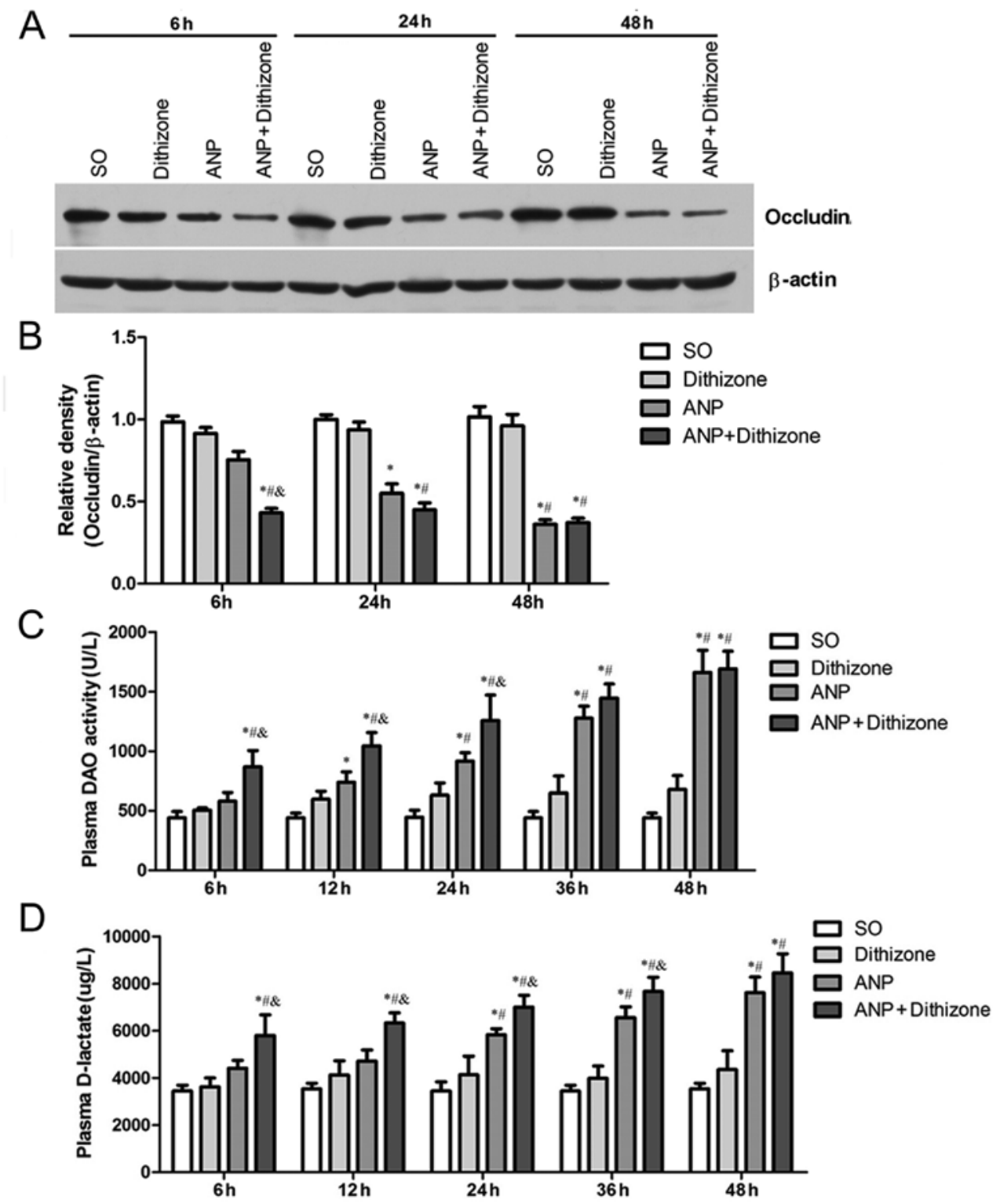

Figure 5. Changes in the intestinal barrier permeability. (A) Western blot analysis of the protein expression level of the tight junction protein occludin (B) Semi-quantification of the western blot analysis. (C) Plasma levels of DAO. (D) Plasma levels of D-lactate. "P<0.05 vs. SO group; ${ }^{\text {PP }}<0.05$ vs. dithizone group; ${ }^{\circledR} \mathrm{P}<0.05$ vs. ANP group. SO, sham-operated group; ANP, acute necrotizing pancreatitis; DAO, diamine oxidase.

A

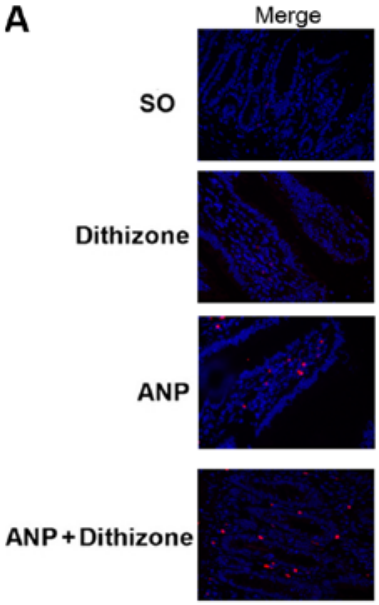

FISH
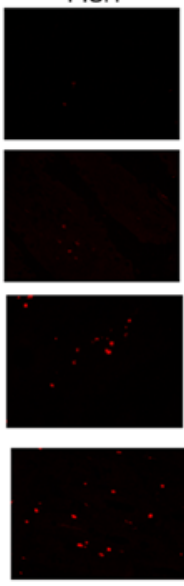

DAPI

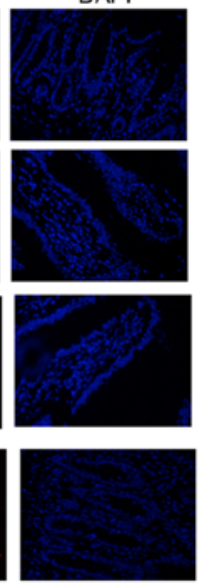

\section{B}

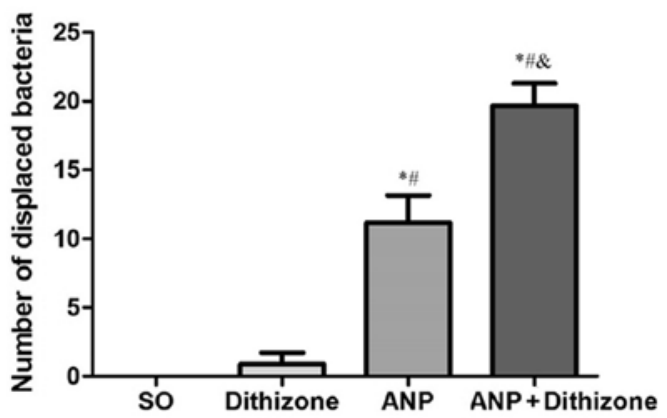

Figure 6. Visualization of the intestinal microbiota translocation by FISH. (A) Sections were hybridized with the universal bacterial probe EUB-338, (red), and stained with the nuclear marker DAPI, (blue). (B) Quantification of the FISH results. "P<0.05 vs. SO group; ${ }^{*} \mathrm{P}<0.05$ vs. dithizone group; ${ }^{\&} \mathrm{P}<0.05$ vs. ANP group. FISH, fluorescence in situ hybridization; SO, sham-operated group; ANP, acute necrotizing pancreatitis. 

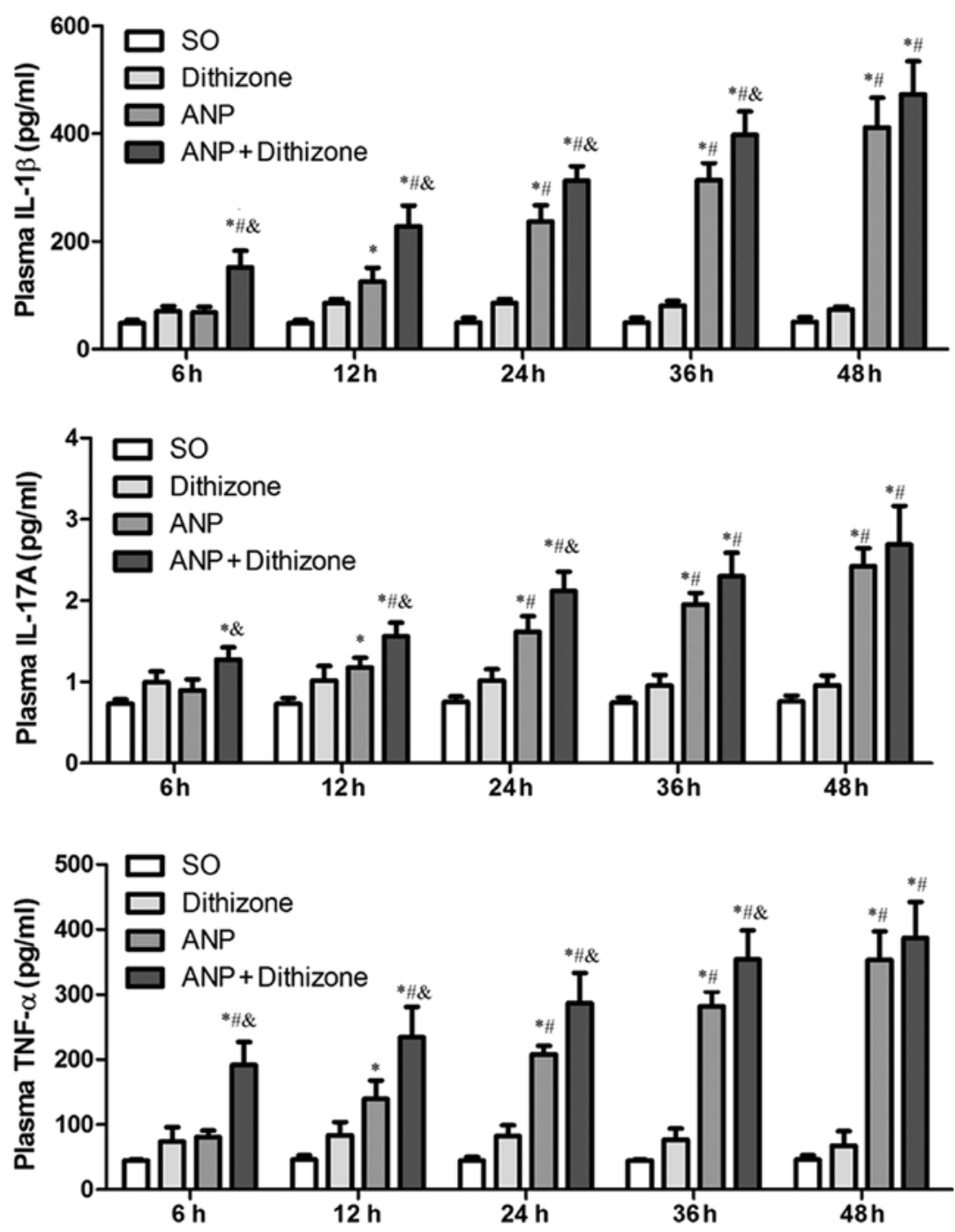

Figure 7. Expression levels of inflammatory cytokines in the plasma of rats, as assessed by ELISA. ${ }^{*} \mathrm{P}<0.05$ vs. SO group; ${ }^{\sharp} \mathrm{P}<0.05$ vs. dithizone group; ${ }^{\text {\& }} \mathrm{P}<0.05$ vs. ANP group. SO, sham-operated group; ANP, acute necrotizing pancreatitis; IL, interleukin; TNF- $\alpha$, tumor necrosis factor $\alpha$.

in the present manuscript. Additionally, the number of Paneth cells may decrease in a time-dependent manner in ANP rats. In fact, the present study identified a significant reduction in the number of Paneth cells between the ANP and SO groups at 36 and $48 \mathrm{~h}$; however, the number of Paneth cells was not affected between 6 and $24 \mathrm{~h}$.

In eukaryotic cells, the ER is the organelle responsible for protein folding and assembly. Inflammation, exposure to microbiota, ischemia and hypoxia result in the accumulation of misfolded or unfolded proteins within the ER, which subsequently activate a self-protective response, previously described as the ER stress response or the unfolded protein response (UPR), in order to maintain cellular homeostasis $(5,39)$. The ER stress response involves the ATF6-mediated transcriptional induction of ER chaperone proteins, including BIP, which are able to increase protein folding $(39,40)$. Additionally, UPR causes the transcriptional induction of ER-associated degradation genes via the X-box binding protein-1, which derives from the processing of ATF6 by inositol-requiring enzyme1 $(39,40)$. Furthermore, the ER stress response involves the transcriptional induction of apoptotic genes, such as $\mathrm{C} / \mathrm{EBP}$ homologous protein (CHOP), mediated by ATF6, leading to the removal of damaged cells $(39,40)$. When the ER stress response is maintained, ATF6-mediated upregulation of CHOP may enhance apoptosis of intestinal epithelial cells, including Paneth cells, thus leading to the development and progression of intestinal diseases $(35,37,39,41,42)$. Our previous studies reported that enhanced ER stress is associated with inflammatory response in pancreas and intestinal tissues of rats during ANP $(43,44)$. In addition, the absence of Paneth cells impairs the function of the intestinal barrier in limiting bacterial translocation, increasing the susceptibility of the small intestine to inflammation, resulting in intestinal injury and ER stress (37). Therefore, in the present study, the protein expression levels of BIP and ATF6 were investigated with the aim to determine whether the ER stress response is associated with Paneth cells loss in ANP. In the present study, the protein expression levels of BIP and ATF6 were significantly upregulated in the ANP group compared with the SO group, which may be a consequence or a cause of Paneth cells loss. Additionally, the protein expression levels of BIP and ATF6 were higher in the ANP + dithizone group than in the ANP group at 6 and $24 \mathrm{~h}$, suggesting that Paneth cell depletion may further aggravate intestinal ER stress, activate inflammatory signaling pathways 


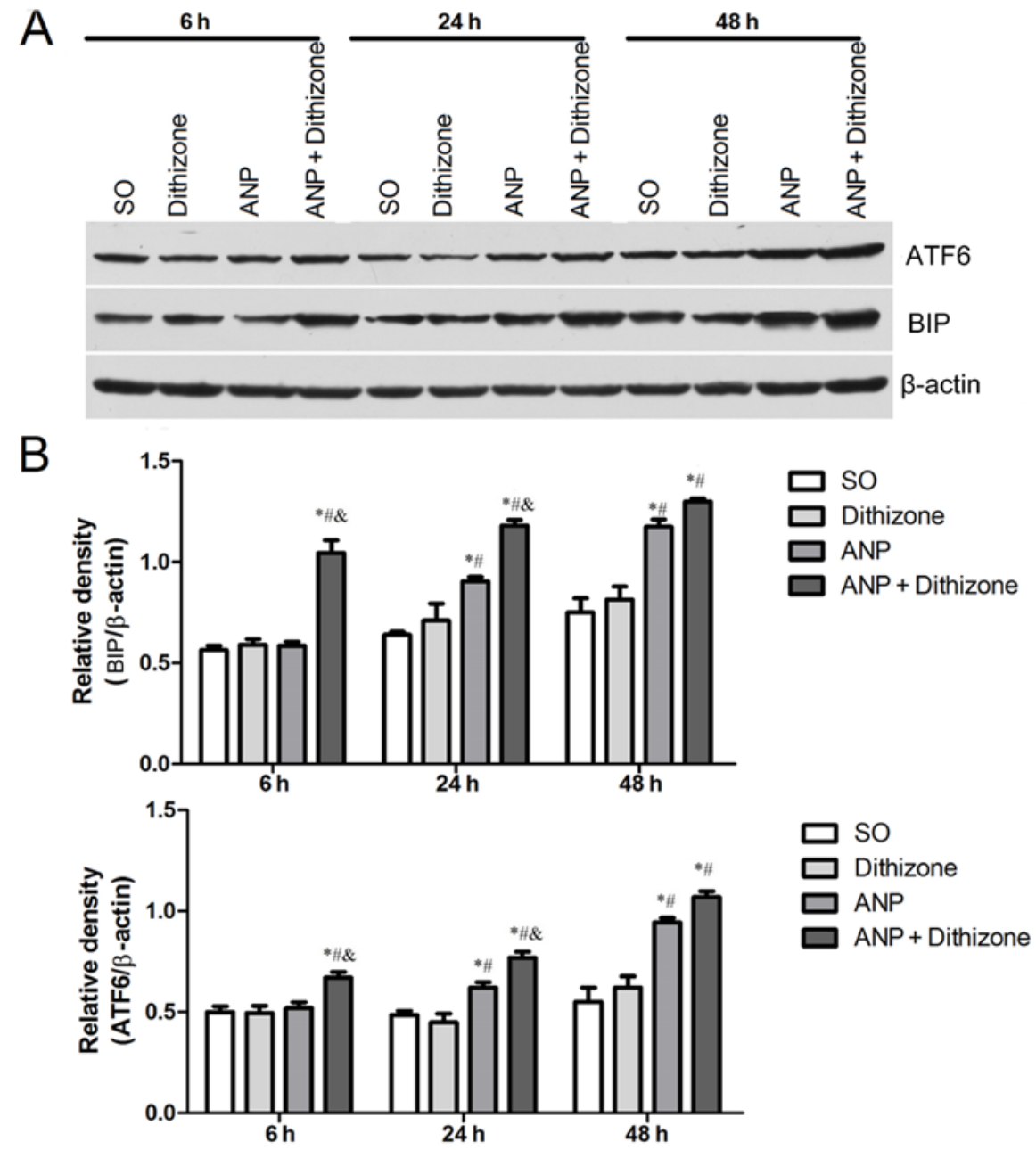

Figure 8. Protein expression levels of the endoplasmic reticulum stress-associated factors BIP and ATF6. (A) Western blotting results. (B) Semi-quantification of the western blotting results. ${ }^{\mathrm{P}}<0.05$ vs. $\mathrm{SO}$ group; ${ }^{\sharp \mathrm{P}}<0.05$ vs. dithizone group; ${ }^{\circledR} \mathrm{P}<0.05$ vs. ANP group. SO, sham-operated group; ANP, acute necrotizing pancreatitis; BIP, binding-immunoglobulin protein; ATF6, activating transcription factor- 6 .

and upregulate the expression of inflammatory cytokines, thus aggravating the intestinal mucosal damage during ANP. Therefore, the present results suggested that the increased ER stress may be involved in the pathogenesis of intestinal barrier dysfunction during ANP and associated with Paneth cells loss. Targeted inhibition of ER stress by 4-phenylbutyric acid may inhibit inflammatory responses and Paneth cells loss, alleviating the symptoms of ANP (44).

A limitation of the present study was that the number of Paneth cells gradually recovered after injection of dithizone, influencing the investigation of the long-term effects of Paneth cells. Therefore, additional studies using mice with genetic defects in Paneth cells are required (45). Additionally, the present study was performed to preliminarily examine the roles of Paneth cells in ANP, and the effects of Paneth cells on intestinal stem cell proliferation and differentiation $(14,15)$ require further investigation. Furthermore, the therapeutic potential of strategies aiming to increase the number of Paneth cells to treat ANP requires further validation (18).

Collectively, the present findings suggested that malfunction of Paneth cells exacerbated intestinal and pancreas damage, aggravated intestinal barrier impairment, increased the expression levels of inflammatory cytokines in plasma and intestinal tissues, promoted the translocation of intestinal bacteria and reduced lysozyme expression in the distal ileum during ANP. Additionally, the increase in intestinal ER stress may be one of the mechanisms associated with Paneth cells loss and intestinal barrier impairment during ANP.

\section{Acknowledgements}

Not applicable.

\section{Funding}

The present study was supported by funds from The Medical-Engineering Cross Project of Shanghai Jiao Tong University (grant nos. YG2015MS29 and YG2014ZD10).

\section{Availability of data and materials}

All data generated or analyzed during the present study are included in this published article.

\section{Authors' contributions}

LL, YG, YZ and XW designed the study. LL and YG performed the experiments. JZ, YL, YS and CH collected and interpreted 
the data. LL and YG drafted the manuscript. YZ and XW revised the manuscript. All authors read and approved the final manuscript.

\section{Ethics approval and consent to participate}

All experimental protocols were approved by The Animal Care and Use Committee of of The Shanghai General Hospital of Nanjing Medical University and the experiments were performed in accordance with the institutional animal care guidelines.

\section{Patient consent for publication}

Not applicable.

\section{Competing interests}

The authors declare that they have no competing interests.

\section{References}

1. Reid GP, Williams EW, Francis DK and Lee MG: Acute pancreatitis: A 7 year retrospective cohort study of the epidemiology, aetiology and outcome from a tertiary hospital in Jamaica. Ann Med Surg 20: 103-108, 2017.

2. Roberts SE, Morrisonrees S, John A, Williams JG, Brown TH and Samuel DG: The incidence and aetiology of acute pancreatitis across Europe. Pancreatology 17: 155-165, 2017.

3. Petrov MS, Shanbhag S, Chakraborty M, Phillips AR and Windsor JA: Organ failure and infection of pancreatic necrosis as determinants of mortality in patients with acute pancreatitis. Gastroenterology 139: 813-820, 2010.

4. Sternby H, Bolado F, Canaval-Zuleta HJ, Marra-López C, Hernando-Alonso AI, Del-Val-Antoñana A, García-Rayado G, Rivera-Irigoin R, Grau-García FJ, Oms L, et al: Determinants of severity in acute pancreatitis: A nation-wide multicenter prospective cohort study. Ann Srrg 18: 2018.

5. Ammori BJ: Role of the gut in the course of severe acute pancreatitis. Pancreas 26: 122-129, 2003.

6. Liu H, Li W, Wang X, Li J and Yu W: Early gut mucosal dysfunction in patients with acute pancreatitis. Pancreas 36: 192-196, 2008.

7. Wang YL, Zheng YJ, Zhang ZP, Su JY, Lei RQ, Tang YQ and Zhang SD: Effects of gut barrier dysfunction and NF-kappaB activation on aggravating mechanism of severe acute pancreatitis. J Dig Dis 10: 30-40, 2009.

8. Yasuda T, Takeyama Y, Ueda T, Shinzeki M, Kishi S, Sawa H, Nakajima T and Kuroda Y: Protective effect of caspase inhibitor on intestinal integrity in experimental severe acute pancreatitis. J Surg Res 138: 300-307, 2007.

9. Yasuda T, Takeyama Y, Ueda T, Shinzeki M, Sawa H, Nakajima T and Kuroda Y: Breakdown of intestinal mucosa via accelerated apoptosis increases intestinal permeability in experimental severe acute pancreatitis. J Surg Res 135: 18-26, 2006.

10. Zhong Y, Cai D, Cai W, Geng S, Chen L and Han T: Protective effect of galactooligosaccharide-supplemented enteral nutrition on intestinal barrier function in rats with severe acute pancreatitis. Clin Nutr 28: 575-580, 2009.

11. Lu F, Feng W, Chen $Z$ and Huang H: Effect of mesenchymal stem cells on small intestinal injury in a rat model of acute necrotizing pancreatitis. Stem Cell Res Ther 8: 12, 2017.

12. Zhang XP, Jie Z, Song QL and Chen HQ: Mechanism of acute pancreatitis complicated with injury of intestinal mucosa barrier. J Zhejiang Univ Sci B 8: 888-895, 2007.

13. Lee C, Minich A, Li B, Miyake H, Seo S and Pierro A: Influence of stress factors on intestinal epithelial injury and regeneration. Pediatr Syrg Int 34: 155-160,2018.

14. Fukuda M, Mizutani T, Mochizuki W, Matsumoto T, Nozaki K, Sakamaki Y, Ichinose S, Okada Y, Tanaka T, Watanabe M and Nakamura T: Small intestinal stem cell identity is maintained with functional Paneth cells in heterotopically grafted epithelium onto the colon. Genes Dev 28: 1752-1757, 2014.
15. Sato T, van Es JH, Snippert HJ, Stange DE, Vries RG, van den Born M Barker N, Shroyer NF, van de Wetering M and Clevers H: Paneth cells constitute the niche for Lgr5 stem cells in intestinal crypts. Nature 469: 415-418, 2011.

16. Nalapareddy K, Nattamai KJ, Kumar RS, Karns R, Wikenheiserbrokamp KA, Sampson LL, Mahe MM, Sundaram N, Yacyshyn MB, Yacyshyn B, et al: Canonical wnt signaling ameliorates aging of intestinal stem cells. Cell Rep 18: 2608-2621, 2017

17. Rodríguez-colman MJ, Schewe M, Meerlo M, Stigter E, Gerrits J, Prasraves M, Sacchetti A, Hornsveld M, Oost KC, Snippert HJ, et al: Interplay between metabolic identities in the intestinal crypt supports stem cell function. Nature 543: 424-427, 2017.

18. Cazorla SI, Maldonadogaldeano C, Weill R, De JP and Perdigón G: Oral administration of probiotics increases paneth cells and intestinal antimicrobial activity. Front Microbiol 9: 736, 2018.

19. Holly MK and Smith JG: Paneth cells during viral infection and pathogenesis. Viruses 10: pii: E225, 2018.

20. Gassler N: Paneth cells in intestinal physiology and pathophysiology. World J Gastrointest Pathophysiol 8: 150-160, 2017.

21. Chen J, Huang C, Wang J, Zhou H, Lu Y, Lou L, Zheng J, Tian L, Wang X, Cao Z and Zeng Y: Dysbiosis of intestinal microbiota and decrease in paneth cell antimicrobial peptide level during acute necrotizing pancreatitis in rats. Plos One 12: e0176583, 2017.

22. Huang C, Chen J, Wang J, Zhou H, Lu Y, Lou L, Zheng J, Tian L, Wang X, Cao Z and Zeng Y: Dysbiosis of intestinal microbiota and decreased antimicrobial peptide level in paneth cells during hypertriglyceridemia-related acute necrotizing pancreatitis in rats. Front Microbiol 8: 776, 2017.

23. Sawada M, Takahashi K, Sawada S and Midorikawa O: Selective killing of Paneth cells by intravenous administration of dithizone in rats. Int J Exp Pathol 72: 407-421, 1991.

24. Zhang C, Sherman MP, Prince LS, Bader D, Weitkamp JH, Slaughter JC and Mcelroy SJ: Paneth cell ablation in the presence of Klebsiella pneumoniae induces necrotizing enterocolitis (NEC)-like injury in the small intestine of immature mice. Dis Model Mech 5: 522-532, 2012.

25. Zhang XP, Ye Q, Jiang XG, Ma ML, Zhu FB, Zhang RP and Cheng QH: Preparation method of an ideal model of multiple organ injury of rat with severe acute pancreatitis. World J Gastroenterol 13: 4566-4573, 2007.

26. Schmidt J, Rattner DW, Lewandrowski K, Compton CC, Mandavilli U, Knoefel WT and Warshaw AL: A better model of acute pancreatitis for evaluating therapy. Ann Surg 215: 44-56, 1992.

27. Chiu CJ, Scott HJ and Gurd FN: Intestinal mucosal lesion in low-flow states. II. The protective effect of intraluminal glucose as energy substrate. Arch Surg 101: 484-488, 1970.

28. Chen S, Xia Y, Zhu G, Yan J, Tan C, Deng B, Deng J, Yin Y and Ren W: Glutamine supplementation improves intestinal cell proliferation and stem cell differentiation in weanling mice. Food Nutr Res 62, 2018.

29. Park SW, Chen SW, Kib M, Brown KM, Kolls JK, D'Agati VD and Lee TH: Cytokines induce small intestine and liver injury after renal ischemia or nephrectomy. Lab Invest 91: 63-84, 2011.

30. Martinez Rodriguez NR, Eloi MD, Huynh A, Dominguez T, Lam AH, Carcamo-Molina D, Naser Z, Desharnais R, Salzman NH and Porter E: Expansion of paneth cell population in response to enteric Salmonella enterica serovar typhimurium infection. Infect Immun 80: 266-275, 2012.

31. Suzuki T: Regulation of intestinal epithelial permeability by tight junctions. Cell Mol Life Sci 70: 631-659, 2013.

32. Al-Sadi R, Khatib K, Guo S, Ye D, Youssef M and Ma T: Occludin regulates macromolecule flux across the intestinal epithelial tight junction barrier. Am J Physiol Gastrointest Liver Physiol 300: G1054-G1064, 2011.

33. Luk GD, Bayless TM and Baylin SB: Diamine oxidase (histaminase). A circulating marker for rat intestinal mucosal maturation and integrity. J Clin Invest 66: 66-70, 1980.

34. Murray MJ, Barbose JJ and Cobb CF: Serum D(-)-lactate levels as a predictor of acute intestinal ischemia in a rat model. J Surg Res 54: 507-509, 1993.

35. Ohashi W, Kimura S, Iwanaga T, Furusawa Y, Irié T, Izumi H, Watanabe T, Hijikata A, Hara T, Ohara O, et al: Zinc transporter SLC39A7/ZIP7 promotes intestinal epithelial self-renewal by resolving ER stress. Plos Genetics 12: e1006349, 2016. 
36. Luo K and Cao SS: Endoplasmic reticulum stress in intestinal epithelial cell function and inflammatory bowel disease. Gastroenterol Res Pract 2015: 328791, 2015.

37. Grootjans J, Hodin CM, de Haan JJ, Derikx JP, Rouschop KM, Verheyen FK, van Dam RM, Dejong CH, Buurman WA and Lenaerts K: Level of activation of the unfolded protein response correlates with paneth cell apoptosis in human small intestine exposed to ischemia/reperfusion. Gastroenterology 140: 529-539, 2011.

38. White JR, Gong H, Pope B, Schlievert P and Mcelroy SJ: Paneth-cell-disruption-induced necrotizing enterocolitis in mice requires live bacteria and occurs independently of TLR4 signaling. Dis Model Mech 10: 727-736, 2017.

39. Chotikatum S, Naim HY and El-Najjar N: Inflammation induced ER stress affects absorptive intestinal epithelial cells function and integrity. Int Immunopharmacol 55: 336-344, 2018.

40. Hetz C: The unfolded protein response: Controlling cell fate decisions under ER stress and beyond. Nat Rev Mol Cell Biol 13: 89-102, 2012

41. Ma X, Dai Z, Sun K, Zhang Y, Chen J, Yang Y, Tso P, Wu G and $\mathrm{Wu} Z$ : Intestinal epithelial cell endoplasmic reticulum stress and inflammatory bowel disease pathogenesis: An update review. Front Immunol 8: 1271, 2017.
42. Cao SS: Endoplasmic reticulum stress and unfolded protein response in inflammatory bowel disease. Inflamm Bowel Dis 21: 636-644, 2015.

43. Zheng J Wu J, Chen J, Liu J, Lu Y, Huang C, Hu G, Wang X and Zeng Y: Therapeutic effects of quercetin on early inflammation in hypertriglyceridemia-related acute pancreatitis and its mechanism. Pancreatology 16: 200-210, 2016.

44. Wu J,Hu G, Lu Y,Zheng J, Jing C, Wang X and Yue Z: Palmitic acid aggravates inflammation of pancreatic acinar cells by enhancing unfolded protein response induced CCAAT-enhancer-binding protein $\beta$-CCAAT-enhancer-binding protein $\alpha$ activation. Int J Biochem Cell Biol 79: 181-193, 2016.

45. Riba A, Olier M, Lacroixlamandé S, Lencina C, Bacquié V, Harkat C, Gillet M, Baron M, Sommer C, Mallet V, et al: Paneth cell defects induce microbiota dysbiosis in Mice and promote visceral hypersensitivity. Gastroenterology 153: 1594-1606, 2017.

(i) $\ominus$ This work is licensed under a Creative Commons Attribution-NonCommercial-NoDerivatives 4.0 International (CC BY-NC-ND 4.0) License. 